\title{
Charpy Impact Resistances of Carbon Nanotubes Reinforced High Density Polyethylene Nanocomposite Materials
}

\author{
Murat Mirik, Şerafettin Ekinci, and Mustafa Taşyürek
}

\begin{abstract}
In this study, Multiwall Carbon Nanotubes (MWCNT) reinforced High Density Polyethylene (HDPE) materials were used. Mechanical properties of the samples reinforced with Carbon Nanotubes at weight ratios of $1 \%, 3 \%$ and $5 \%$ were investigated. Reinforced samples were compared to samples produced with pure High density Polyethylene. Samples were produced by plastic injection method. The samples were then subjected to experiments and impact resistance values were measured in accordance with ASTM D6110 standards. Also Thermogravimetric Analyses (TGA) was performed for and Multi-Wall Carbon Nanotubes within the High Density Polyethylene. At the end of the study, it was observed that impact resistance decreased with increasing carbon nanotube reinforcement amount. Impact resistance of samples produced by means of plastic injection was decreased by $35 \%$ comparing with samples produced from pure HDPE. These results were explained with the fact that structures of composite materials were transformed to a tougher and fragile phase. In the TGA investigations, it was seen that mass loss breakdown temperature and melting point temperature increased by MCWNT ratio in the composite samples.
\end{abstract}

Index Terms-Carbon nanotubes, high density polyethylene, nanocomposites, impact, TGA.

\section{INTRODUCTION}

Since the documented discovery of CNTs in 1991 by Iijima [1] and the realization of their unique physical properties, including mechanical, thermal, and electrical, many investigators have endeavored to fabricate advanced CNT composite materials that exhibit one or more of these properties [2]-[4]. For example, as conductive filler in polymers, CNTs are quite effective compared to traditional carbon black microparticles, primarily due to their large aspect ratios [5]. Similarly, CNTs possess one of the highest thermal conductivities known [6], which suggests their use in composites for thermal management [2].

The main focus of this paper, however, will be on the use of CNTs as discontinuous reinforcement for polymer matrices. The CNT can be thought of as the ultimate carbon fiber with break strengths reported as high as $200 \mathrm{GPa}$, and elastic module in the 1TPa range [7], [8].

Manuscript received July 28, 2015; revised October 8, 2015.

Murat Mirik is with Cumhuriyet University, Sivas Vocational School, Sivas, Turkey (e-mail: mmirik@cumhuriyet.edu.tr).

Serafettin Ekinci is with Selcuk University, Technology Faculty, Mechanical Engineering Department, Konya, Turkey (e-mail: sekinci@selcuk.edu.tr).

Mustafa Taşyürek is with Selcuk University, Technology Faculty, Metallurgical and Material Engineering Department, Konya, Turkey (e-mail: mtasyurek@selcuk.edu.tr).
CNTs are graphitic sheets rolled into seamless tubes (i.e. arrangements of carbon hexagons into tube like fullerenes) having a diameter ranging from about a nanometer to tens of nanometers with lengths up to centimeters. Both theoretical and experimental studies have shown CNTs to have extremely high tensile module ( $>1$ TPa for single walled carbon nanotubes, SWCNTs) and tensile strengths of the order of $500 \mathrm{GPa}$ [9], [10]. Carbon nanotubes are thermally stable up to over $2400^{\circ} \mathrm{C}$ in vacuum, have a thermal conductivity along their principal axes about double than that of diamond and electric-current-carrying capacity up to 1000 times higher than copper wire. Due to their extraordinary mechanical, electrical and optical properties together with their low density $\left(1.3-2.4 \mathrm{~g} / \mathrm{cm}^{3}\right)$, CNTs have attracted great attention in recent years in the field of composites materials. As the structure and properties of the CNTs have been understood, there is a pressing need to transfer their outstanding properties from nano to micro/macro-scales. One essential step towards this goal is their processing, which often involves dispersing them in a polymeric matrix to form complex materials such as polymer-CNTs nanocomposites. These composites represent the first realized major commercial application of CNTs [11].

The addition of nanostructured materials, such as CNTs, to polymers offers a viable means of altering the mechanical [12], [13], thermal [3]-[14] and electrical [15], [16] properties of polymer-based composite materials. The resulting properties include tensile strengths of 100-600 GPa, a density of around $1.3 \mathrm{~g} / \mathrm{cm}^{3}$, elastic module of 200-5000 GPa and fracture strains of 10-30\% [17], [18]. CNTs have desirable mechanical properties that make them particularly attractive for strengthening polymers [19].

\section{MAterials AND MethodS}

This section with High Density Polyethylene multiwalled carbon nanotube formed into a composite material which comprises the experiments. Properties of carbon nanotube are given at Table I, and properties of thermoplastic matrix are given at Table II.

The samples used in this study, is available from Fibermax Composites Multi-Walled Carbon Nanotubes with PETKIMM Petrochemical Holding CO. is located in Izmir Aliaga. Quality Control and Technical Services Manager facilities are connected to the work done, again obtained from PETKIM F00556 combined with High Density Polyethylene was granulated.

Impact test samples were produced within the required 
measures to be implemented in accordance with the ASTM D6110 standard. Granules were produced in the sample by pressing the plastic injection molding machine. These samples were subjected to tests according to standard ASTM D6110. Thermogravimetric Analysis (TGA) was performed according to the ASTM E1131 standard.

\begin{tabular}{lc}
\multicolumn{2}{c}{ TABLE I: THE PHYSICAL PROPERTIES OF MWCNT } \\
\hline \hline Average Diameter & $10-40 \mathrm{~nm}$ \\
Length & $1-25 \mu \mathrm{m}$ \\
Purity & Min. $93 \%$ \\
Specific Surface Area & $150-250 \mathrm{~mm}^{2}$ \\
\hline \hline & \\
\hline \hline & TABLE II: THE PROPERTIES OF HDPE \\
\hline Melt Flow Rate (g/10dk) & 0,04 \\
Density (g/cm ${ }^{3}$ ) & 0,956 \\
Pour in the tensile strength (MPa) & 22,555 \\
Tensile Strength at Break (MPa) & 29,420 \\
Elongation at Break (\%) & $>500$ \\
Melting Point $\left({ }^{\circ} \mathrm{C}\right)$ & 131 \\
\hline \hline
\end{tabular}

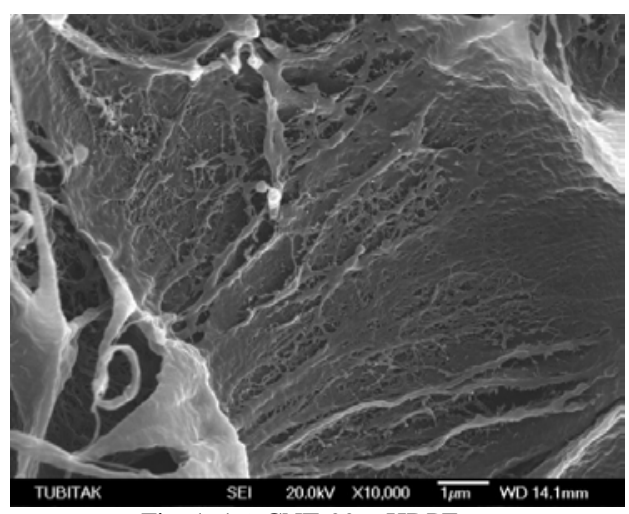

Fig. 1. 1\% CNT-99\% HDPE.

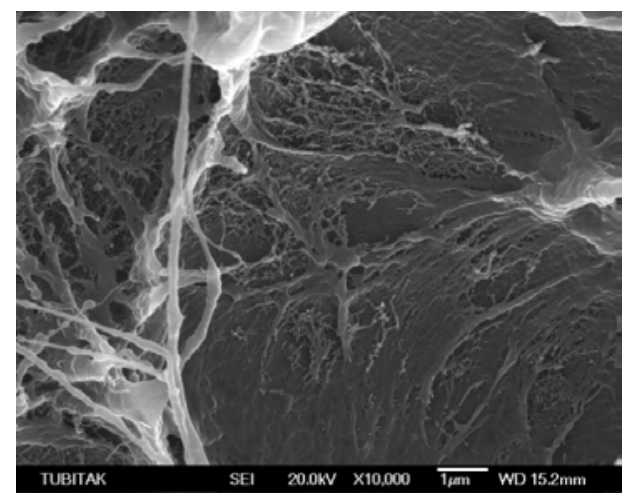

Fig. 2. 3\% CNT-97\% HDPE.

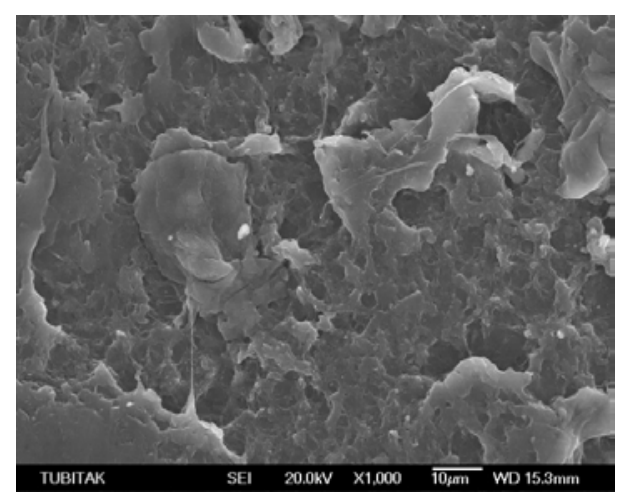

Fig. 3. 5\% CNT-95\% HDPE

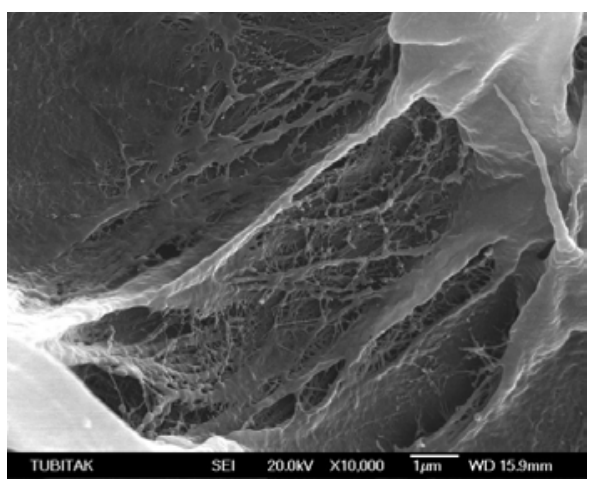

Fig. 4. 0\% CNT-100\% HDPE.

First, samples were weighed in a beaker using a BP $310 \mathrm{~S}$ precision balance with $0.001 \mathrm{~g}$ accuracy. About 2.500 grams of sample were considered for each sample. MWCNTs were mixed with HDPE in weight ratios of $0 \%, 1 \%, 3 \%$ and $5 \%$ using a mixer; a hot mix was created using an extruder and given the desired shape by cutting from the resulting sample using a cutting machine. A German made TYYSSEN HENSCHEL model HENSCHEL Mischer FM10C Type electric double mixer, which was present in Petkim plastic processing plant, was used to stir each sample using a blade mixer with a speed of $525 \mathrm{rpm}$ at room temperature for 10 min. The initial mixture temperature of $27^{\circ} \mathrm{Chas}$ reached $47^{\circ}$ Cafter 10 minutes. Mixed materials were then subjected to hot mixture using BRABENDER PLASTI-CORDER PL2000 model, L/D double screw extruder, situated in the R\&D facilities, with the ratio of 18 and output speed of 50 $\mathrm{rpm}$. The extruder with 4 heating zones was heated at $170^{\circ} \mathrm{C}$, $190^{\circ} \mathrm{C}, 200^{\circ} \mathrm{Cand} 190^{\circ} \mathrm{Cin}$ that order and molten composite mixture leaving the extruder was cooled down by passing through a water tank connected to a thermostat unit using water cooling and crushed using a mechanical crusher to obtain small pieces of the granule. Experiment samples were obtained by the molding the samples prepared as granules in plastic injection molds prepared according to the ASTM D6110 standard under a pressure of $40 \mathrm{MPa}$ and $20 \mathrm{sec}$ at ironing temperature and $30 \mathrm{sec}$ at refrigeration temperature under $200^{\circ} \mathrm{C}, 180^{\circ} \mathrm{C}, 180^{\circ} \mathrm{C}, 180^{\circ} \mathrm{C}$ in that order using a German made 1996 Arburg Spritzgie Bmaschine brand 270-E-50-210 type plastic injection machine. SEM images are given in the Fig. 1, Fig. 2, Fig. 3 and Fig. 4.

\section{RESUlTS AND DISCUSSION}

ASTM D6110 standard samples prepared by the impact of the tests, KOMPEN CO. Ladik plants in the Quality Control Laboratory Ceast mark Resil Impactor model 6967 type impact tests were performed using a hammer $2 \mathrm{~J}$ device. The experimental results in Table III and Fig. 5 are given.

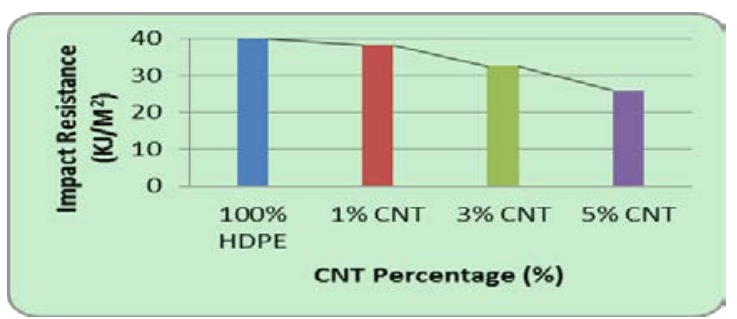

Fig. 5. Manufactured by plastic injection impact test results graph of samples. 
TABLE III: PLASTIC INJECTION MOLDING TABLE COMPARISON OF THE RESULTS OF THE IMPACT TEST SAMPLES

\begin{tabular}{|c|c|c|c|c|c|}
\hline \multicolumn{2}{|r|}{ SPECIMEN } & $\begin{array}{c}0 \% \text { CNT } \\
100 \% \\
\text { HDPE } \\
\end{array}$ & $\begin{array}{c}1 \% \mathrm{CNT} \\
99 \% \\
\mathrm{HDPE}\end{array}$ & $\begin{array}{c}3 \% \text { CNT } \\
97 \% \\
\text { HDPE } \\
\end{array}$ & $\begin{array}{c}5 \% \text { CNT } \\
95 \% \\
\text { HDPE }\end{array}$ \\
\hline \multirow{3}{*}{$\begin{array}{l}\text { Z } \\
\text { O } \\
\text { 䛼 } \\
\text { 党 }\end{array}$} & $\begin{array}{l}\text { Ingested } \\
\text { energy (J) }\end{array}$ & 1.994 & 1.908 & 1.616 & 1.291 \\
\hline & Area $\left(\mathrm{mm}^{2}\right)$ & 49.875 & 49.875 & 49.875 & 49.875 \\
\hline & $\begin{array}{l}\text { Impact } \\
\text { resistance } \\
\left(\mathrm{KJ} / \mathrm{m}^{2}\right)\end{array}$ & 39.984 & 38.248 & 32.397 & 25.887 \\
\hline & $\begin{array}{l}\text { \% Change } \\
\text { mpared to pure } \\
\text { HDPE }\end{array}$ & $0 \%$ & $-4.34 \%$ & $-18.98 \%$ & $-35.26 \%$ \\
\hline
\end{tabular}

During TGA, a change in mass of the material heated with a controlled speed under a suitable atmosphere is measured using a very accurate electronic scale. The sample is heated with a suitable temperature program by selecting a gas suitable for the sample's properties, after weighing the sample on TGA device scale (5 - $20 \mathrm{mg})$. Usually, a speed of $10^{\circ} \mathrm{C} / \mathrm{min}$ speed and gas flow of $50 \mathrm{ml} / \mathrm{min}$ up to $1000^{\circ} \mathrm{C}$ is programmed for polymer samples. Nitrogen atmosphere is replaced by air at $600^{\circ} \mathrm{C}$. The amount of change in the mass of the sample is recorded as a function of time or temperature. Weight loss within desired temperature range is calculated in mg on the thermogram drawn. Curves 1 and 2 can be differentiated; mathematical calculations can be made between curves. TGA/SDTA device is used in determining material type by analyzing, moisture, volatile matter, ash analysis and dissolved material, thermal decomposition, oxidation, all kinds of thermal behavior of polymers and various organic / inorganic based materials. The temperature range in which the polymer is pyrolyzed provides a means for identifying polymers or polymer mixtures, as different polymers have different decomposition kinetics. Monitoring exothermic and endothermic peaks with the SDTA signal also provides additional information on material melting and degradation. It has been raised to $1000^{\circ} \mathrm{C}$ with $10^{\circ} \mathrm{C} / \mathrm{min}$ heating speed in PETKIMM Petrochemicals CO R\&D Laboratory using METTLER brand TGA/STGA 851 E according to the ASTM E1131 standard and nitrogen and atmosphere air were used as gas. As the crystallinity of the polymer composites is having influence on Young's modulus and toughness, it was decided to study thermal analysis of the composites, i.e. DSC and TGA. In the case of DSC curves, which are shown in Fig. 6, the addition of CNTs in HDPE increases the total enthalpy of crystallization. The melting point of composites occurred at about $137^{\circ} \mathrm{C}$ indicating the degree of polymer crystallinity in all composites.

The reinforcement of CNTs in HDPE is not affected the melting point of the composites. In case of TGA curves which are shown in Fig. 7, thermal stabilization of CNTs-HDPE composites and the fraction of volatile components are observed with an atmosphere of air. It is observed that the onset temperatures of these composites are $405.76^{\circ} \mathrm{C}, 417.50^{\circ} \mathrm{C}, 420.05^{\circ} \mathrm{C}$ and $430.32^{\circ} \mathrm{C}$ for pure HDPE, $1 \%$, $3 \%$ and $5 \%$ CNTs, respectively. It is observed that onset temperature decreases with an addition of chemically treated CNTs due to amorphous carbon present in the CNTs and other carbonaceous impurities that oxidize at temperature lower than that of CNTs. The oxidation temperature of composites, thermal stability of the composites, is found by differentiating the percentage of weight loss curve with temperature which is shown in Fig. 8.

The temperatures at which the maximum rate of oxidation is taking place are $492.28^{\circ} \mathrm{C}, 493.02^{\circ} \mathrm{C}, 488.78^{\circ} \mathrm{C}$ and $481.56^{\circ} \mathrm{C}$ for $5 \%, 3 \%, 1 \%$ and HDPE, respectively. It is observed that the oxidation temperature of the composite is not much affected by the addition of CNTs, which may be due to very low fraction of CNTs in the composites.

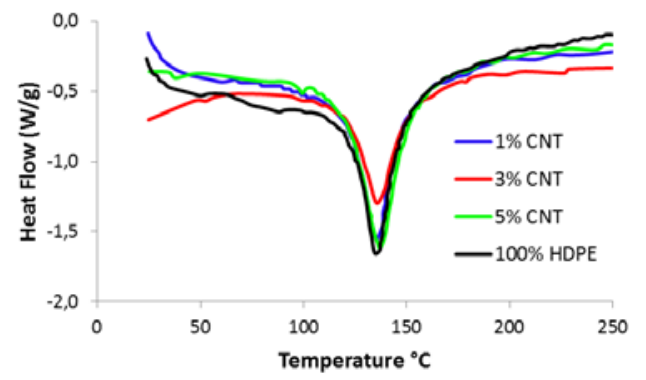

Fig.6. DSC curves of CNT-HDPE composites.

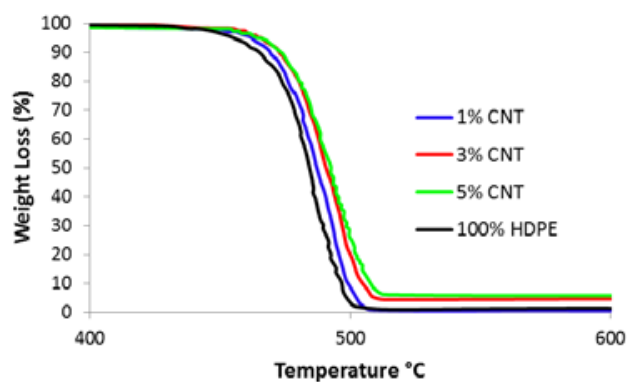

Fig.7.TGA curves of CNT-HDPE composites.

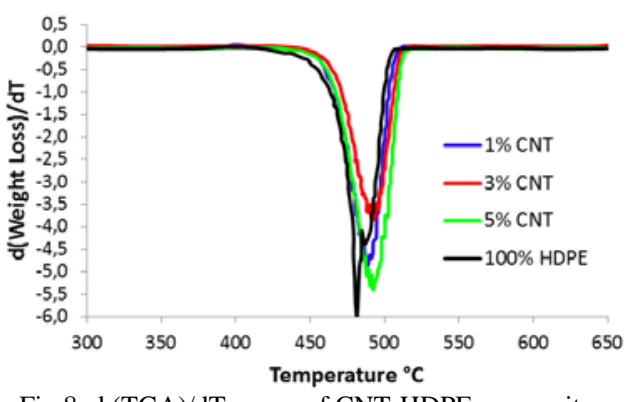

Fig.8. d (TGA)/dTcurves of CNT-HDPE composites.

\section{CONCLUSION}

In this study, High Density Polyethylene (HDPE) into a 1 wt $\%, 3 \%$ and 5\% participating multi-walled carbon nanotubes (MWCNT) granules, making itself after the plastic injection samples production methods impact resistance how to alter examined. However, the outcomes and recommendations are:

1) Multi-Walled Carbon Nanotubes with High Density Polyethylene in a mixture of primarily mechanical mixture directly without the use of any chemical substance mixed with granules were obtained in the extruder. We have tried to provide practicality and advantages for mass production.

2) The weight ratio of the composite increases impact strength decrease of MWCNT material was transformed into a fragile structure that is richer than us. Impact strength, the pure by High Density Polyethylene; 4.34\% in $1 \%$ MWCNT contribute, to contribute 3\% MWCNT 
$18.98 \%$, 35.26\% in 5\% contribution MWCNT 'health has fallen. According to these results is the value of the good impact strength of pure HDPE $\left(39.984 \mathrm{KJ} / \mathrm{m}^{2}\right)$.

3) TGA analysis of the composite by weight ratio increases MWCNT distortion temperature increased mass loss. Depending on the temperature, the lowest value of the mass loss rate of $3 \%$ mass loss rate value in the MWCNT is additive. This increased ratio of the weight of the material MWCNT mass loss temperature and a melting point to reduce the rate of melting temperature was found to slightly increase.

4) High Density Polyethylene into a more homogeneous dispersion of MWCNT impact strength by working to reach a higher value.

5) Impact of the microstructure of the fracture surfaces of samples examined fracture properties of MWCNT may have an impact on how they will lead to fatigue and wear properties can be examined.

\section{ACKNOWLEDGMENT}

The data of paper were taken from Murat Mirik’s Ms. Thesis [20].

\section{REFERENCES}

[1] S. ijima, "Helical microtubules of graphitic carbon,” Nature, vol. 354, pp. 56-58, Nov.1991.

[2] M. J. Biercuk, M. C. Llaguno, M. Radosvljevic, J. K. Hyun, and A. T. Johnson, "Carbon nanotube composites for thermal management," Appl. Phys. Lett, vol. 80, no. 15, pp. 2767-2769, April 2002.

[3] Z. Ounaies, C. Park, K. E. Wise, E. J. Siochi, and J. S. Harrison, "Electrical properties of single wall carbon nanotube reinforced polyimide composites," Compos. Sci. Technol., vol. 63, no.11, pp.1637-1646, Aug. 2003.

[4] M. C. Weisenberger, E. A. Grulke, and D. Jacques, T. Rantell, R. Andrews, "Enhanced mechanical properties of polyacrylonitrile/multiwall carbon nanotube composite fibers," $J$. Nanosci. Nanotechno., vol. 3, no. 6, pp. 535-539, Dec. 2003.

[5] D. T. Colbert, "Single-wall nanotubes: a new option for conductive plastics and engineering polymers," Plast. Add. Comp., vol. 5, no. 1, pp.18-25, June 2003.

[6] P. Kim, L. Shi, A. Majumdar, and P. L. McEuen, "Thermal transport measurements of individual multiwalled nanotubes," Phys. Rev. Lett., vol. 87, no. 21, pp. 215502-1-4, Nov. 2001.

[7] K. T. Lau and D. Hui, "The revolutionary creation of new advanced materials-carbon nanotube composites," Compos Part B-Eng., vol. 33, no. 4, pp. 263-277, June 2002.

[8] B. G. Demczyk, Y. M. Wang, J. Cumings, M. Hetman, W. Han, A. Zettl et al., "Direct mechanical measurement of the tensile strength and elastic modulus of multiwalled carbon nanotubes,” Mat. Sci. Eng. A-Struct., vol. 334, no. 1-2, pp. 173-178, Sep. 2002.

[9] E. T. Thostenson, Z. Ren, and T. W. Chou, "Advances in the science and technology of carbon nanotubes and their composites: A review," Compos. Sci. Technol., vol. 61, no. 13, pp. 1899-1912, Oct. 2001.

[10] O. Lourie, D. M. Cox, and H. D. Wagner, "Buckling and Collapse of Embedded Carbon Nanotubes,” Phys. Rev. Lett., vol. 81, no. 8, pp. 1638-1641, Aug. 1998.
[11] R. H. Baughman, A. A. Zakhidov, and W. A. De Heer, "Carbon nanotubes--the route toward applications," Science, vol. 297, no. 5582, pp.787-792, Aug. 2002.

[12] Z. Yang, B. Dong, Y. Huang, L. Liu, F. Yan, and H. Li, "A study on carbon nanotubes reinforced poly(methyl methacrylate) nanocomposites," Mater. Lett., vol. 59, no. 17, pp. 2128-2132, July 2005.

[13] D. Qian, E. C. Dickey, R. Andrews, and T. Rantell, "Load transfer and deformation mechanisms in carbon nanotube-polystyrene composites," Appl. Phys. Lett, vol. 76, no. 20, pp. 2868-2870, May 2000.

[14] J. Q. Pham, C. A. Mitchell, J. L. Bahr, J. M. Tour, R. Krishanamoorti, and P. F. Green, "Glass transition of polymer/single-walled carbon nanotube composite films," J. Polym. Sci. Pol. Phys., vol. 41, no. 24, pp. 3339-3345, Nov. 2003

[15] J. Sandler, M. S. P. Shaffer, T. Prasse, W. Bauhofer, K. Schulte, and A. H. Windle, "Development of a dispersion process for carbon nanotubes in an epoxy matrix and the resulting electrical properties," Polymer, vol. 40, no. 21, pp. 5967-5971, Oct. 1999

[16] M. Pumera, A. Merkoci, and S. Alegret, "Carbon nanotube-epoxy composites for electrochemical sensing," Sensor. Actuat. B-Chem., vol. 113, no. 2, pp. 617-622, Feb. 2006.

[17] O. Breuer and U. Sundararaj, "Big returns from small fibers: A review of polymer/carbon nanotube composites," Polym. Composite., vol. 25, no. 6, pp. 630-645, Dec. 2004.

[18] A. Desai and M. Haque, "Mechanics of the interface for carbon nanotube polymer composites," Thin Wall. Struct., vol. 43, no. 11, pp. 1787-1803, Nov. 2005.

[19] L. Ci and J. Bai, "The reinforcement role of carbon nanotubes in epoxy composites with different matrix stiffness," Compos. Sci.Technol., vol. 66, no. 3-4, pp. 599-603, March 2006.

[20] M. Mirik, "The investigation of the mechanical properties of carbon nanotubes reinforced high density polyethylene (HDPE) nanocomposite materials," M. S. thesis, Institute of Science and Technology, Selçuk University, Konya, Turkey, 2010.

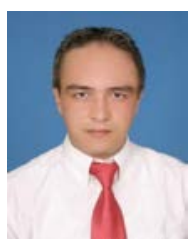

Murat Mirik was born in 1982, who received his master degree in machine training from Selçuk University, Turkey in 2010. Currently, he is a lecturer at the rail systems machine technology programme, Cumhuriyet University, Turkey.

His main research interest includes nanocomposite materials. He is a member of IACSIT.

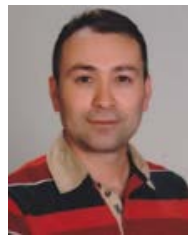

Serafettin Ekinci is with the Department of Mechanical Engineering, Technology Faulty, Selçuk University, Konya, Turkey. He was born in Sivas, Turkey, 1971, who received his Ph.D in agricultural machineries from Konya, Turkey in September 2011, with major field of study focused on traction mechanics.

His research interests are traction performance, tire and tribology. He is a member of IACSIT.

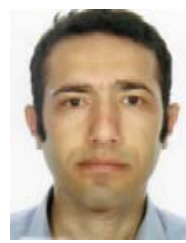

Mustafa Taşyürek was born in 1982, who received his $\mathrm{PhD}$ degree in mechanical education from Selçuk University, Turkey in 2014. From 2005 to present, he is a research assistant with Selçuk University. Currently, he is a research assistant at the Department of Metallurgical and Materials Engineering, Selçuk University, Turkey.

His research interests are biofuels, nanomaterials, nanocomposites and mechanical properties. He is a member of IACSIT. 